Johnson \& Wales University ScholarsArchive@JWU

Health \& Wellness Department Faculty

Publications and Research

College of Health \& Wellness

$9-2018$

\title{
Alcohol Advertising on Facebook and the Desire to Drink Among Young Adults
}

Jonathan K. Noel

Johnson \& Wales University - Providence, Jonathan.Noel@jwu.edu

Thomas F. Babor

Follow this and additional works at: https://scholarsarchive.jwu.edu/health_fac

Part of the Medicine and Health Sciences Commons

\section{Repository Citation}

Noel, Jonathan K. and Babor, Thomas F., "Alcohol Advertising on Facebook and the Desire to Drink Among Young Adults" (2018). Health o Wellness Department Faculty Publications and Research. 35.

https://scholarsarchive.jwu.edu/health_fac/35 


\title{
Alcohol Advertising on Facebook and the Desire to Drink Among Young Adults
}

\author{
JONATHAN K. NOEL, PH.D., M.P.H., ${ }^{a, *} \&$ THOMAS F. BABOR, PH.D., M.P.H. ${ }^{a, \dagger}$ \\ ${ }^{a}$ University of Connecticut School of Medicine, Department of Community Medicine and Health Care, Farmington, Connecticut
}

\begin{abstract}
Objective: Social networking sites (SNSs) may influence the behavior of SNS users by exposing them to information about the number of other users who engaged with a SNS post (i.e., user engagement) and any comments left in response to a post (i.e., user-generated comments [UGCs]). The current study hypothesized that beer advertisements with higher user engagement levels and pro-drinking UGCs would be positively associated with the desire to drink and ad engagement. The effect of ad content in relation to regulatory compliance was also investigated. Method: A 2 (regulatory compliant vs. noncompliant) $\times 2$ (low vs. high user engagement) $\times 2$ (pro- vs. anti-alcohol UGC) mixed factorial experiment was used. A total of 120 young adults viewed two compliant and two noncompliant ads. Participants were randomized
\end{abstract}

into four groups: ads with high or low user engagement values, which were paired with either pro- or anti-drinking UGCs. Dependent variables included desire to drink and engaging (i.e., Liking or Sharing) with the ad. Results: When associated with high user engagement values, the desire to drink was 3.5 times greater in the pro-drinking UGC group compared with the anti-drinking UGC group (odds ratio $=3.48,95 \%$ CI $[1.60,7.55])$. Ad engagement was 2.3 times greater among those exposed to pro-drinking UGCs (odds ratio $=2.30,95 \%$ CI $[1.09,4.85]$ ). Conclusions: Pro-drinking comments may increase the desire to drink and ad engagement, both of which may be predictive of future drinking behavior. Regulations are needed to limit the ability of SNS users to engage with alcohol ads. (J. Stud. Alcohol Drugs, 79, 751-760, 2018)
$\mathrm{S}_{\mathrm{e}}^{\mathrm{Y}}$ YSTEMATIC REVIEWS HAVE SUGGESTED that exposure to alcohol advertising can, at least moderately, increase alcohol consumption in adolescents (Jackson et al., 2018; Jernigan et al., 2017; Scott et al., 2017). Although the focus has primarily been on exposure to traditional media advertising (e.g., television, print), new media channels, specifically social networking sites (SNSs), are becoming an important platform for marketing alcoholic beverages (Jernigan \& Rushman, 2014; Lobstein et al., 2017). For example, hundreds of corporate-sponsored alcohol-branded pages have been located on Facebook (Nhean et al., 2014); there were more than 40 million Likes, Shares, and Comments on the Facebook pages of the 15 most consumed alcohol brands among youth as of March 2013 (Jernigan \& Rushman, 2014); and alcohol ads have generated millions of views on YouTube (Winpenny et al., 2014).

Exposure to SNS alcohol ads may be associated with increased alcohol consumption. For example, engagement with alcohol-related SNS content was predictive of greater alcohol consumption and engagement in other risky behaviors (Hoffman et al., 2014). Among U.S. college students,

Received: February 12, 2018. Revision: July 16, 2018.

The study was funded by a fellowship from the Beever Trust Fund.

*Correspondence may be sent to Jonathan K. Noel at the University of Connecticut School of Medicine, Department of Community Medicine and Health Care, 263 Farmington Avenue, Farmington, CT, or via email at: jknoel@hotmail.com. ‘Because Thomas F. Babor is Editor of the Journal of Studies on Alcohol and Drugs, the review of this article was partially blinded by removing his name from the list of authors when the article was reviewed. Neither the reviewers, the assistant field editor, nor the field editor (who made the final decision) was informed that Dr. Babor was one of the authors until after the article review was concluded. This was done to prevent real or apparent conflicts of interest. drinking intentions were significantly greater after viewing Facebook ads associated with high user engagement (Alhabash et al., 2015), and in 2015, 35\% of Pinterest users bought an alcoholic beverage after seeing a Pin containing alcohol (Kumar, 2016).

SNS ads, defined as images, videos, and text published by a consumer brand on a corporate-sponsored, branded SNS account, are unique relative to ads in traditional media channels because they encourage interactivity and engagement. SNS users can engage with a SNS post through the user engagement functions (e.g., the Like function on Facebook) or by writing a comment immediately below the post, known as a user-generated comment (UGC).

In general, larger user engagement values for SNS advertising are associated with more favorable viewer responses (Koroleva et al., 2011; Paek et al., 2013), and positive associations between the number of Likes a Facebook ad received and consumer attitudes toward a brand, involvement with a brand, brand trust, and purchase intentions have been reported (Phua \& Ahn, 2016). For alcohol-related SNS ads, the relationship between Liking a Facebook alcohol ad and future drinking intentions was greatest for ads with a high number of Likes and Shares (Alhabash et al., 2015).

Research on the impact of comments is limited. The ratio of positive to negative comments on a branded post was positively associated with the number of post Likes and comments (de Vries et al., 2012). Another study concluded that negative comments may significantly diminish viewers' positive impressions of a company or brand (Haigh \& Shelly, 2015).

In the United States, SNS alcohol ads are governed by a voluntary self-regulatory system created by the alcohol industry (International Center for Alcohol Policies, 2011, 
2014). Using a series of exposure and content guidelines, the system is designed to limit alcohol advertising exposure among youth and to prevent youth and other vulnerable populations from being exposed to harmful ad content. Regulatory compliance indicates that youth are not disproportionately exposed to alcohol advertising and that alcohol advertising does not promote excessive alcohol use; using alcohol in dangerous situations; using alcohol for social, physical, financial, or sexual success; or content that is primarily appealing to youth or addresses at-risk groups (e.g., pregnant women). Little data are available to demonstrate its effectiveness governing SNS ads. Fifty Facebook ads published by Bud Light and Budweiser were compared to the alcohol industry's content guidelines; $82 \%$ of the ads were deemed noncompliant by a panel of public health experts (Noel \& Babor, 2017). Studies of the exposure guidelines have not yet been published, although several studies have concluded that large proportions of youth are aware of SNS alcohol advertising and have interacted with alcohol-branded SNS accounts (Collins et al., 2016; Hoffman et al., 2014; Lin et al., 2012).

The purpose of this study was to determine if user engagement levels and comments associated with SNS alcohol ads could influence the desire to drink and measures of ad engagement. The potential impact of ad content, based on regulatory compliance, was also investigated. Based on previous empirical evidence (Alhabash et al., 2015; Haigh \& Shelly, 2015), it was hypothesized that high user engagement values and pro-drinking comments would significantly increase the desire to drink and ad engagement. Because alcohol marketing regulation intends to protect vulnerable populations, it was hypothesized that noncompliant ad content would also significantly increase the desire to drink and ad engagement.

\section{Method}

The study sought to determine if user engagement values and UGCs displayed alongside SNS alcohol ads can significantly increase the desire to drink and ad engagement. The study also sought to determine if ad content, based on regulatory compliance, had a similar effect. The study used a 2 (ad regulatory compliance: compliant vs. noncompliant) $\times 2$ (user engagement: low vs. high) $\times 2$ (UGC type: pro- vs anti-alcohol) mixed factorial design. Participants viewed four SNS alcohol ads that varied based on ad content (a within-subjects effect). User engagement values and UGCs were displayed alongside each ad, and participants were randomized to view either (a) high user engagement values/ pro-drinking UGCs, (b) high user engagement values/antidrinking UGCs, (c) low user engagement values/pro-drinking UGCs, or (d) low user engagement values/anti-drinking UGCs (between-subjects effects). Desire to drink and ad engagement were assessed after each ad exposure.

\section{Participants}

In all, 120 young adults, 21-24 years old, were recruited through Amazon Mechanical Turk. Additional inclusion criteria were living in the United States and having Internet access. There were no exclusion criteria. A two-stage recruitment procedure was used. First, a public invitation to a screening survey was posted on Amazon Mechanical Turk. Then, studyeligible individuals were identified and sent a private invitation to participate. Respondents were reimbursed $\$ 0.05$ for completing the screening survey and $\$ 10.00$ for completing the study. Of the 1,759 individuals screened, 200 (11\%) met the inclusion criteria, and 120 (7\%) completed the study. All participants completed the study (100\%).

\section{Advertisement selection}

Four Facebook ads were selected from a previous evaluation of Facebook ads published by Bud Light and Budweiser (Noel \& Babor, 2017). For each brand, one ad was compliant with the code and the other was noncompliant. A content analysis was used to match each compliant ad with a samebrand noncompliant ad to ensure that ad content was similar in as many respects as possible except for the content that caused noncompliance (Noel \& Babor, 2017). The ads used have been published elsewhere (Noel et al., 2018a). Noncompliant ads promoted excessive alcohol consumption (a Budweiser ad) and associated alcohol use with success (a Bud Light ad). Compliant ads focused on product quality (a Budweiser ad) and promoted the airing of a television commercial (a Bud Light ad).

\section{User engagement values}

User engagement values were defined as the number of Likes, Shares, and Comments associated with the Facebook ad. Each ad was associated with a set of real-world values elicited by Bud Light or Budweiser Facebook ads. Participants were randomized to view either high (e.g., "27k Likes," "11k Shares," "4.5k Comments") or low user engagement values (e.g., "216 Likes," "22 Shares," "12 Comments"). Extreme high and low user engagement values were purposefully selected to elicit a large between-group difference. At the time of the study, it was unknown whether there was a specific user engagement value where potential effects would begin to appear.

\section{UGC selection}

UGCs were defined as comments associated with the Facebook ad that were published by non-brand-affiliated Facebook users. Each ad was associated with a set of realworld UGCs written in response to Bud Light or Budweiser Facebook ads (Noel \& Babor, 2017). Each set consisted of 
two unique comments, replicating the number displayed on Facebook. A thematic content analysis was used to identify pro- and anti-drinking UGCs (Noel et al., 2018a). Pro-drinking UGCs were randomly selected from the "positive consequences" (e.g., "Some call it a six pack I call it my support group") and "past drinking" (e.g., "I done had so many of these tonight lol") themes. Anti-drinking UGCs were randomly selected from the "negative consequences" (e.g., "I lost a friend behind your product. U guys suck") and "abstinence/sobriety" (e.g., "i don't even drink or smoke, can't say i miss this") themes. Participants were randomized to view either pro- or anti-drinking UGCs. The ads, user engagement values, and UGCs used are published in Supplemental Figure 1 of Noel et al. (2018a).

\section{Dependent variables}

Dependent variables included desire to drink and ad engagement. Desire to drink was assessed using one item (France et al., 2014). Participants were asked if the ad would increase or decrease the desire to drink in "an individual like them." Responses were measured on a 5-point Likert scale, ranging from definitely decrease (coded as 0) to definitely increase (coded as 4). The question used the reference frame "an individual like them" in order to separate the issue from the participant and elicit more reliable responses (Bradburn et al., 2004).

Ad engagement is the use of a SNS's user engagement functions. Ad engagement was operationalized by assessing a participant's level of agreement with two statements: "I would 'Like' this Facebook post" and "I would 'Share' this Facebook post with my Friend network." Responses on the 5-point Likert scale ranged from strongly disagree to strongly agree. Ad engagement was included because use the Like or Share function increases ad exposure and serves as a product recommendation, which is a strong predictor of future product use (Reichheld, 2003).

\section{Covariates}

Demographic variables included age, sex, race, ethnicity, household income, and marital status. Others have reported that these variables may influence alcohol use levels (e.g., Collins, 2016; Karlamangla et al., 2006; Molander et al., 2010; Moore et al., 2005) or alcohol ad perceptions (Noel et al., 2018b; Proctor et al., 2005). Facebook involvement, defined as use and trust of the information found on Facebook, was included to control for familiarity with SNSs. It was measured using a 29-item scale designed specifically for use with Facebook (Rauniar et al., 2014). Possible scores ranged from 0 to $145(\alpha=.93)$. Alcohol involvement was measured with the Alcohol Use Disorders Identification Test (AUDIT), which consisted of 10 questions measuring past-year alcohol use, alcohol dependence symptoms, and harmful alcohol use (Saunders et al., 1993). Possible scores ranged from 0 to $40(\alpha=.83)$, reflecting abstinence/low-risk drinking $(0-7)$, hazardous drinking (8-15), harmful alcohol use (16-19), or alcohol dependence $(\geq 20)$ (Babor \& Robaina, 2016). AUDIT scores were previously associated with alcohol ad perceptions (Noel et al., 2018b).

\section{Study procedure}

Study procedures have been described elsewhere (Noel et al., 2018a). Briefly, the study was conducted online. Participants were randomized and viewed four ads within one of four test conditions sequentially. Desire to drink and ad engagement questions were completed after each exposure. A Latin Square design was used to ensure each group viewed the ads in a unique order. Covariates were measured after all ad exposures. The UConn Health Institutional Review Board approved this procedure as exempt.

\section{Statistical analysis}

Each continuous independent variable was found to be normally distributed after an examination for skewness and kurtosis. Differences in demographic variables across study groups were tested using independent $t$ tests and chi-square analysis. The significance of main and interactive effects was assessed using hierarchical linear modeling (HLM), which was selected to model cross-level interactions and to adjust for the clustering of responses within participants. Two-level random-intercept, random-slope HLM models were specified. Level 1 consisted of ad content. Level 2 consisted of user engagement, UGCs, and the covariates. The following interactions were also assessed: User Engagement $\times$ UGCs, User Engagement $\times$ Ad Content, UGCs $\times$ Ad Content, and User Engagement $\times$ UGCs $\times$ Ad Content. The cross-level interactions were specified by including the between-subjects effects as Level 2 variables of the Level 1 ad slope. The reference groups were compliant ads, low user engagement values, anti-drinking UGCs, men, White, non-Hispanic, and single, never married. The general form of the adjusted models were:

$$
\begin{aligned}
& Y_{i j}=\pi_{o j}+\pi_{l j(\text { ad content })}+e_{i j} \\
& \pi_{o j}=\beta_{00}+\beta_{01}(\text { user engagement })+\beta_{02}(\text { UGCs })+ \\
& \beta_{03}(\text { user engagement } * \text { UGCS })+\beta_{04}(\text { age })+\beta_{05}(\text { sex })+ \\
& \left.\beta_{06} \text { (race }\right)+\beta_{07}(\text { ethnicity })+\beta_{08}(\text { income })+\beta_{09}(\text { marital } \\
& \text { status })+\beta_{010}(\text { AUDIT })+\beta_{011}(\text { Facebook involvement }) \\
& +r_{0 i} \\
& \pi_{1 i}=\beta_{10}+\beta_{11}(\text { user engagement })+\beta_{12}(\text { UGCs })+ \\
& \beta_{13}(\text { user engagement } * \text { UGCs })+r_{l i},
\end{aligned}
$$

where $Y_{i j}$ represented the dependent variable, $\pi_{i j}$ represented the within-subject coefficients, $\beta_{i j}$ represented the betweensubjects coefficients, $r_{0 i}$ represented the random intercept, $r_{I i}$ 
TABLE 1. Participant demographics

\begin{tabular}{|c|c|c|}
\hline Variable & $M$ & $S D$ \\
\hline Age, years & 22.7 & 1.1 \\
\hline AUDIT score & 5.8 & 5.9 \\
\hline Facebook involvement & 82.3 & 16.5 \\
\hline \multirow[t]{2}{*}{ Income } & $\begin{array}{c}\$ 40,000- \\
\$ 49,999\end{array}$ & $\$ 30,000$ \\
\hline & Count & $\%$ \\
\hline \multicolumn{3}{|l|}{$\operatorname{Sex}^{a}$} \\
\hline Male & 61 & 50.8 \\
\hline Female & 58 & 48.3 \\
\hline \multicolumn{3}{|l|}{ Ethnicity } \\
\hline Hispanic & 16 & 13.3 \\
\hline Non-Hispanic & 104 & 86.7 \\
\hline \multicolumn{3}{|l|}{ Race } \\
\hline American Indian/Native Alaskan & 2 & 1.7 \\
\hline Asian & 15 & 12.5 \\
\hline Black American & 12 & 10.0 \\
\hline White & 82 & 68.3 \\
\hline Other & 3 & 2.5 \\
\hline Two or more races & 6 & 5.0 \\
\hline \multicolumn{3}{|l|}{ Marital status $^{a}$} \\
\hline Single, never married & 106 & 88.3 \\
\hline Married, or domestic partnership & 11 & 9.2 \\
\hline Widowed & 1 & 0.8 \\
\hline Divorced & 1 & 0.8 \\
\hline Separated & 0 & 0.0 \\
\hline
\end{tabular}

Notes: AUDIT $=$ Alcohol Use Disorders Identification Test. ${ }^{a}$ One missing value.

represented the random slope, and $e_{i j}$ represented the model error term.

Desire to drink was specified as a five-category ordinal variable with a logit link function. The ordinal HLM model used a cumulative odds model whereby the relative odds of a unit increase in an independent variable was assumed to be independent of the level of the dependent variable. Under this assumption, odds ratios (ORs) are interpreted as the probability of being at or below a given value of the dependent variable. For this reason, the desire-to-drink scale was reversed, which allowed model ORs to be classically interpreted (e.g., an OR $>1$ indicates being more likely to have a greater desire to drink).

For ad engagement, the Liking and Sharing items were first dichotomized because of high positive skew and a substantial floor effect (i.e., the most common response was strongly disagree). The responses agree and strongly agree were collapsed into an affirmative category. The responses strongly disagree, disagree, and neither were collapsed into a reference group. The variables were then combined. If a participant responded in the affirmative that they would Like or Share an ad, the response was coded as 1. In turn, the reference group was not affirmatively Liking and not affirmatively Sharing an ad. Therefore, the analysis determined the odds of a participant agreeing to Like or Share versus not agreeing to Like or Share. For ad engagement, the Bernoulli distribution was specified with a logit link function.

Significant interactions were investigated by first identifying all possible group combinations of the interacting variables. For example, four groups are created from a significant interaction between user engagement and UGCs: high user engagement values/pro-drinking UGCs, high user engagement values/anti-drinking UGCs, low user engagement values/pro-drinking UGCs, and low user engagement values/anti-drinking UGCs. Then, the outcome variable was graphed across each group and ad exposure, and new models were created using each new group as a comparison group.

All models used a homogeneous covariance structure and were estimated using the penalized quasi-likelihood method. Age, income, AUDIT score, and Facebook involvement score were grand-mean centered. All other variables were un-centered. Unconditional models, with no predictors, were specified to determine intraclass correlations (ICCs), which represented the amount of variance of the dependent variables explained by the clustering of responses within participants. Statistical significance was set at $\alpha=.05$. The analysis was performed using HLM for Windows Version 7.01 (Scientific Software International, Inc., Skokie, IL).

\section{Results}

\section{Participant characteristics}

Table 1 contains the participant characteristics. The sample consisted primarily of non-Hispanic $(86.7 \%)$, White $(68.3 \%)$, single, never married $(88.3 \%)$ young adults $\left(M_{\text {age }}=\right.$ $22.7)$. Half the sample was male $(50.8 \%)$ and approximately $25 \%$ were non-low-risk drinkers. Demographic variables were not statistically different across study groups. Two participants had missing demographic data and were excluded from the HLM analysis.

\section{Desire to drink}

Mean desire to drink across all ads was 2.1 (range: 2.0-2.2), which was the midpoint of the scale, and ICC = 0.67 . In the unadjusted model, the User Engagement $\times$ UGC interaction was statistically significant $(\mathrm{OR}=3.45,95 \% \mathrm{CI}$ $[1.01,11.8]$ ) (Table 2). The main effects of ad content, user engagement, and UGCs were not statistically significant. After we adjusted for age, sex, race, ethnicity, household income, marital status, Facebook involvement, and AUDIT score, the User Engagement $\times$ UGC interaction remained significant.

The interaction term was first investigated by graphing the mean desire to drink score by experimental group and ad exposure (Figure 1). Subsequent HLM modeling indicated that desire to drink was 3.48 times greater in the high user engagement/pro-drinking UGC group (OR $=3.48,95 \% \mathrm{CI}$ $[1.60,7.55]), 2.73$ times greater in the low user engagement/ pro-drinking UGC group (OR $=2.73,95 \% \mathrm{CI}[1.26,5.91])$, and 2.87 times greater in the low user engagement/antidrinking UGC group $(\mathrm{OR}=2.87,95 \% \mathrm{CI}[1.32,6.28])$ relative to the high user engagement/anti-drinking UGC group. 
TABLE 2. Unadjusted and adjusted odds ratios (ORs) for the effect of ad content, user engagement, and user-generated comments on the desire to drink

\begin{tabular}{|c|c|c|c|c|}
\hline \multirow[b]{2}{*}{ Variable } & \multicolumn{2}{|c|}{ Unadjusted } & \multicolumn{2}{|c|}{ Adjusted } \\
\hline & OR & {$[95 \% \mathrm{CI}]$} & OR & {$[95 \% \mathrm{CI}]$} \\
\hline \multicolumn{5}{|l|}{ Fixed effects-intercept } \\
\hline \multicolumn{5}{|l|}{ User engagement } \\
\hline High user engagement & 0.68 & {$[0.37,1.26]$} & 0.66 & {$[0.39,1.14]$} \\
\hline Low user engagement & - & - & - & - \\
\hline \multicolumn{5}{|l|}{ User-generated comments } \\
\hline Pro-drinking comments & 1.84 & {$[0.99,3.39]$} & 1.82 & {$[1.05,3.15]$} \\
\hline Anti-drinking comments & - & - & - & - \\
\hline \multicolumn{5}{|l|}{ User Engagement $\times$} \\
\hline User-Generated Comments & 3.45 & {$[1.01,11.8]$} & 3.66 & {$[1.24,10.8]$} \\
\hline \multicolumn{5}{|l|}{ Sex } \\
\hline Female & & & 0.44 & {$[0.25,0.78]$} \\
\hline Male & & & - & {$\left[\begin{array}{cl}0.00] \\
-\end{array}\right.$} \\
\hline \multicolumn{5}{|l|}{ Race } \\
\hline Non-White & & & 1.29 & {$[0.71,2.33]$} \\
\hline White & & & - & - \\
\hline \multicolumn{5}{|l|}{ Ethnicity } \\
\hline Hispanic & & & 1.41 & {$[0.63,3.16]$} \\
\hline Non-Hispanic & & & - & - \\
\hline \multicolumn{5}{|l|}{ Marital status } \\
\hline \multicolumn{5}{|l|}{ Married, divorce, } \\
\hline Single, never married & & & - & {$\left[\begin{array}{c}{[.251]} \\
-\end{array}\right.$} \\
\hline Age & & & 0.86 & {$[0.67,1.10]$} \\
\hline Income & & & 1.02 & {$[0.93,1.11]$} \\
\hline AUDIT & & & 1.08 & {$[1.03,1.14]$} \\
\hline Facebook involvement & & & 1.03 & {$[1.01,1.05]$} \\
\hline \multicolumn{5}{|l|}{ Fixed effects-slope } \\
\hline \multicolumn{5}{|l|}{ Ad content } \\
\hline Non-compliant ads & 1.17 & {$[0.81,1.69]$} & 1.18 & {$[0.82,1.70]$} \\
\hline Compliant ads & - & - & - & - \\
\hline \multicolumn{5}{|l|}{ User Engagement $\times$} \\
\hline Ad Content & 0.92 & {$[0.44,1.93]$} & 0.93 & {$[0.45,1.94]$} \\
\hline \multicolumn{5}{|l|}{ User-Generated Comments $\times$} \\
\hline Ad Content & 1.27 & {$[0.60,2.67]$} & 1.25 & {$[0.60,2.60]$} \\
\hline \multicolumn{5}{|l|}{ User Engagement $x$} \\
\hline User-Generated Comments $\times$ & & & & \\
\hline Ad Content & 1.59 & {$[0.36,7.02]$} & 1.54 & {$[0.36,6.67]$} \\
\hline Random effects & $\chi^{2}$ & $p$ & $\chi^{2}$ & $p$ \\
\hline Intercept & 336.8 & $<.001$ & 254.1 & $<.001$ \\
\hline Slope & 97.3 & $>.500$ & 98.1 & $>.500$ \\
\hline
\end{tabular}

Notes: AUDIT $=$ Alcohol Use Disorders Identification Test.

The differences between the other experimental groups were nonsignificant.

In addition, in the adjusted model, the desire to drink was $56 \%$ lower among females ( $\mathrm{OR}=0.44,95 \% \mathrm{CI}[0.25,0.78]$ ), and AUDIT and Facebook involvement scores were statistically significant (Table 2). Each 1 unit increase in AUDIT and Facebook involvement score was associated with an $8 \%$ $(\mathrm{OR}=1.08,95 \% \mathrm{CI}[1.03,1.14])$ and $3 \%(\mathrm{OR}=1.03,95 \%$ CI $[1.01,1.05])$ increase in the desire to drink, respectively.

\section{Ad engagement}

Forty-four percent of participants indicated they would Like or Share at least one Facebook ad, and ICC $=0.66$. In the unadjusted model, none of the main or interactive effects of ad content, user engagement, or UGCs were statistically significant (Table 3). After we adjusted for the covariates, the odds of Liking or Sharing an ad were 2.3 times greater among participants who viewed pro-drinking UGCs (OR = $2.30,95 \%$ CI $[1.09,4.85])$.

AUDIT and Facebook involvement scores were also associated with ad engagement. Each 1 unit increase in the AUDIT and Facebook involvement score was associated with an $8 \%$ $(\mathrm{OR}=1.08,95 \% \mathrm{CI}[1.02,1.14])$ and $4 \%(\mathrm{OR}=1.04,95 \%$ CI $[1.02,1.07])$ increase in ad engagement, respectively.

\section{Discussion}

The findings suggest that pro-drinking comments may increase the desire to drink when coupled with high user en- 


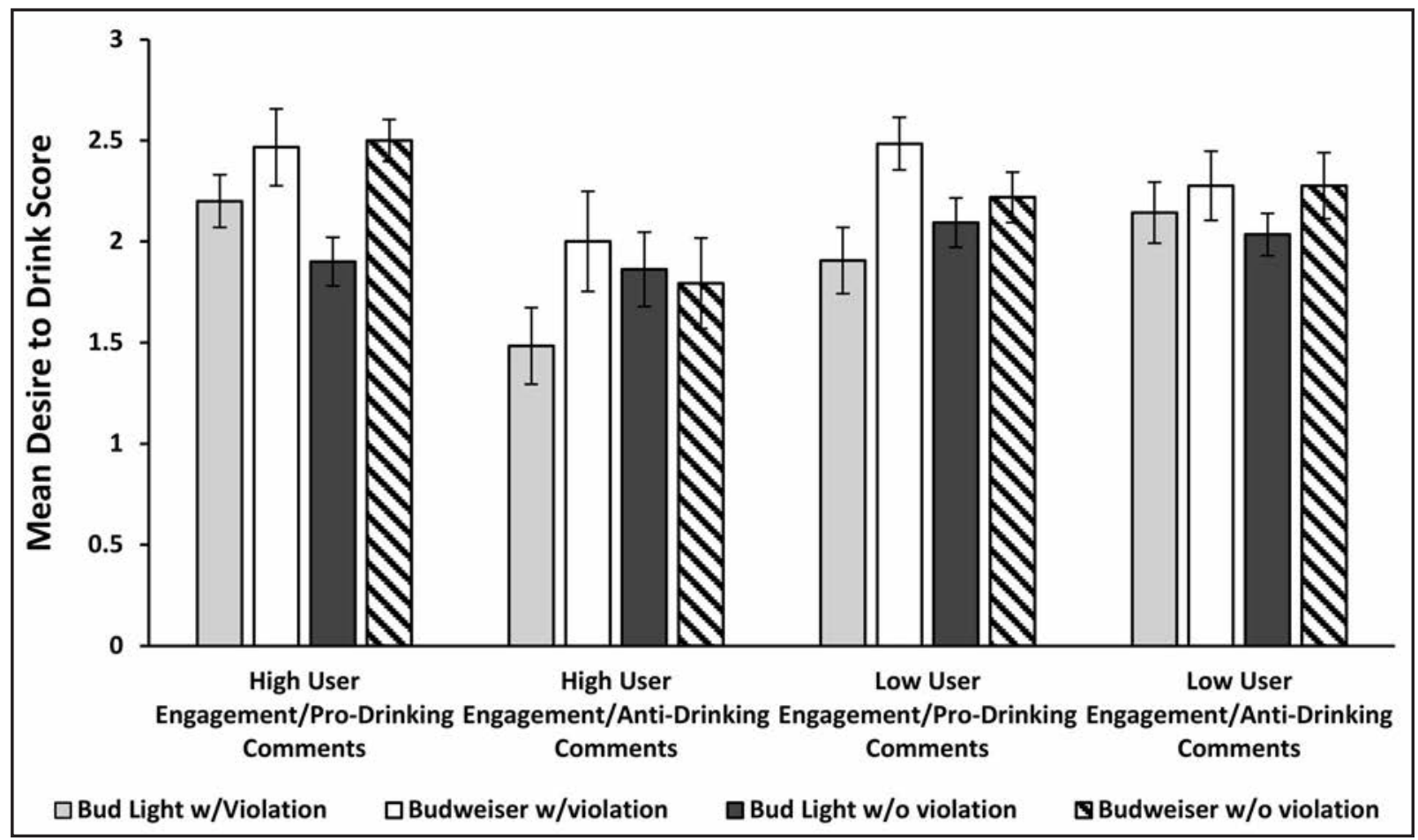

FIGURE 1. Mean desire to drink score by experimental group and ad exposure, with standard error bars

gagement values and may independently increase ad engagement. The findings also suggest that regulatory compliance of ad content and user engagement values may not influence the desire to drink or ad engagement.

\section{Comments as electronic word of mouth}

Information spread through word of mouth is inherently a social phenomenon that can strongly influence behavior (Groeger \& Buttle, 2014). Within the context of SNSs, comments may serve as electronic word of mouth in that SNS users are exposed to a user's thoughts about a SNS post. In this way, comments may act as an information source that can reinforce or negate the ad message (Kim \& Sun, 2006). Importantly, electronic word of mouth may increase product purchases (Meuter et al., 2013; See-To \& Ho, 2014). Positive electronic word of mouth may significantly improve purchase intentions, whereas negative electronic word of mouth may significantly decrease purchase intentions (Lim, 2015; Sandes \& Urdan, 2013; Wu, 2013), although other studies described a more nuanced effect (Kim \& Gupta, 2012; Lee \& Cranage, 2014; Podnar \& Javernik, 2012).

\section{Increasing the desire to drink}

The finding that the desire to drink increased after exposure to pro-drinking comments is consistent with previous research demonstrating that desire to drink increases after exposure to alcohol cues (Schulze \& Jones, 2000), and increases in the desire to drink under laboratory conditions have explained up to $10 \%$ of the variance in later drinking behavior in a sample of alcohol-dependent patients undergoing treatment (Litt et al., 2000). Interestingly, heavy alcohol users and those who are alcohol dependent may be most susceptible to the potential effects of pro-drinking comments. Magnetic resonance imaging studies suggest that areas of the brain associated with addiction differentially activate in heavy alcohol users after exposure to alcohol cues (Myrick et al., 2004; Tapert et al., 2003), and an increased desire to drink after exposure to alcohol cues may predict relapse after treatment for alcoholism (Cooney et al., 1997; Gordon et al., 2006; Litt et al., 2000).

\section{Consequences of ad engagement}

Pro-drinking comments significantly increased the odds of engaging with an SNS beer ad through the Like or Share function, and Liking or Sharing a Facebook ad may indirectly predict future drinking intentions (Alhabash et al., 2015; Lee \& Hong, 2016). Brand identification and brand trust may be higher among those who retweet brand messages on Twitter (Kim et al., 2014), and those with positive attitudes toward a brand may be more likely to share a SNS brand message (Chu \& Sung, 2015). In addition, studies have reported a strong correlation between positive brand attitudes and purchase intentions (Beukeboom et al., 2015; Toldos- 
TABLE 3. Unadjusted and adjusted odds ratios (ORs) for the effect of ad content, user engagement, and user-generated comments on ad engagement

\begin{tabular}{|c|c|c|c|c|}
\hline \multirow[b]{2}{*}{ Variable } & \multicolumn{2}{|c|}{ Unadjusted } & \multicolumn{2}{|c|}{ Adjusted } \\
\hline & OR & {$[95 \% \mathrm{CI}]$} & OR & {$[95 \% \mathrm{CI}]$} \\
\hline \multicolumn{5}{|l|}{ Fixed effects-intercept } \\
\hline \multicolumn{5}{|l|}{ User engagement } \\
\hline High user engagement & 1.23 & {$[0.59,2.56]$} & 1.05 & {$[0.50,2.18]$} \\
\hline Low user engagement & - & - & - & - \\
\hline \multicolumn{5}{|l|}{ User-generated comments } \\
\hline Pro-drinking comments & 1.86 & {$[0.90,3.87]$} & 2.30 & {$[1.09,4.85]$} \\
\hline Anti-drinking comments & - & - & - & - \\
\hline \multicolumn{5}{|l|}{ User Engagement $\times$} \\
\hline User-Generated Comments & 0.60 & {$[0.14,2.60]$} & 0.55 & {$[0.13,2.36]$} \\
\hline \multicolumn{5}{|l|}{ Sex } \\
\hline Female & & & 0.62 & {$[0.29,1.32]$} \\
\hline Male & & & - & - \\
\hline \multicolumn{5}{|l|}{ Race } \\
\hline Non-White & & & 1.80 & {$[0.81,4.04]$} \\
\hline White & & & - & - \\
\hline \multicolumn{5}{|l|}{ Ethnicity } \\
\hline Hispanic & & & 1.65 & {$[0.59,4.57]$} \\
\hline Non-Hispanic & & & - & - \\
\hline \multicolumn{5}{|l|}{ Marital status } \\
\hline \multicolumn{5}{|l|}{ Married, divorce, } \\
\hline Single, never married & & & - & - \\
\hline Age & & & 1.02 & {$[0.73,1.43]$} \\
\hline Income & & & 0.92 & {$[0.81,1.03]$} \\
\hline AUDIT & & & 1.08 & {$[1.02,1.14]$} \\
\hline Facebook involvement & & & 1.04 & {$[1.02,1.07]$} \\
\hline \multicolumn{5}{|l|}{ Fixed effects-slope } \\
\hline \multicolumn{5}{|l|}{ Ad content } \\
\hline Non-compliant ads & 1.47 & {$[0.89,2.41]$} & 1.18 & {$[0.82,1.70]$} \\
\hline Compliant ads & - & - & - & - \\
\hline \multicolumn{5}{|l|}{ User Engagement $x$} \\
\hline Ad Content & 0.96 & {$[0.35,2.58]$} & 0.93 & {$[0.45,1.94]$} \\
\hline \multicolumn{5}{|l|}{ User-Generated Comments $\times$} \\
\hline Ad Content & 1.08 & {$[0.40,2.93]$} & 1.25 & {$[0.60,2.60]$} \\
\hline \multicolumn{5}{|l|}{ User Engagement $x$} \\
\hline User-Generated Comments $\times$ & & & & \\
\hline Ad Content & 1.42 & {$[0.19,10.4]$} & 1.54 & {$[0.36,6.67]$} \\
\hline Random effects & $\chi^{2}$ & $p$ & $\chi^{2}$ & $p$ \\
\hline Intercept & 250.7 & $<.001$ & 208.2 & $<.001$ \\
\hline Slope & 53.7 & $>.500$ & 55.0 & $>.500$ \\
\hline
\end{tabular}

Notes: $\mathrm{CI}=$ confidence interval; AUDIT $=$ Alcohol Use Disorders Identification Test.

Romero \& Orozco-Gómez, 2015). The process of Liking or Sharing a Facebook ad may also increase ad effectiveness. Shared Facebook ads, when viewed by other Facebook users, were reported as more credible and less intrusive compared with direct brand communications (Morris et al., 2016).

\section{Secondary findings}

AUDIT and Facebook involvement scores were positively associated with the desire to drink and ad engagement, suggesting that alcohol use history and SNS use should be considered when estimating the impact of SNS alcohol advertising on future alcohol consumption. The role of Facebook involvement scores was consistent with previous research (Choi \& Scott, 2013; Huang et al., 2012; Sohn,
2009) and may intimate that trustworthiness of information presented on SNSs results from greater SNS use. Moreover, the desire to drink was greatest among men, which may reflect men being the target group of the ads used.

\section{Null findings}

Contrary to study hypotheses, there was no significant main effect of user engagement values or ad content. The null main effect of user engagement values may suggest either a more complex relationship between SNS information and SNS post perceptions than has been previously investigated or that the user engagement values in the "low user engagement" value group were already sufficiently high to product an effect. The null main effect of ad content may 
suggest participant bias toward the included brands. That is, participants may have stereotyped the intended ad message published by each brand regardless of the creative elements used. Alternatively, ad content may have little effect on the desire to drink and ad engagement. Finally, the nonsignificant random slope indicates that the change in the desire to drink and ad engagement across ad exposures was consistent for all study participants, even if the absolute numbers varied.

\section{Implications}

With pro-drinking comments more prevalent than antidrinking comments (Noel et al., 2018), a Facebook user who saw the study ads was more likely to be exposed to the reinforcing effects of pro-drinking comments, and there is little incentive for alcohol producers to regulate comments written in response to their ads. Potential SNS regulations may include restrictions or bans on ad engagement, including the publishing of comments in response to corporate-sponsored alcohol-branded content. This regulatory scheme is being tested in Finland, where new restrictions have effectively banned advertising on SNSs (YLE, 2014).

Programmatically, comments may be used to devise novel health promotion campaigns. Health information may be posted as a comment underneath a post promoting an unhealthy behavior that also received high user engagement. For instance, messages promoting moderate alcohol use or abstinence could be posted underneath a SNS alcohol ad. The message would then be distributed to all Facebook users who view the alcohol ad, and alcohol producers would shoulder the message distribution costs of public health messages.

\section{Limitations}

This study used a relatively small sample size that likely limited overall study power. Significant main effects of user engagement or ad content may be observed in a larger study. Curiously, the main effects of the comments were significant only after covariate adjustment. This may indicate that specific combinations of covariates (e.g., sex and AUDIT score) may have differed between groups. Furthermore, because anti-drinking comments were compared against pro-drinking comments, it is unknown whether pro-drinking comments significantly increase the desire to drink, anti-drinking comments significantly decrease the desire to drink, or both. A similar limitation exists regarding ad engagement. Ad engagement may also be underestimated because only two of the potential forms of SNS engagement were measured in the study.

The study results may not be generalizable to other demographic groups, SNS platforms, or alcohol brands. The study relied on self-report, and because of the anonymous nature of Amazon Mechanical Turk, it was not possible to verify the truthfulness of participant responses. Order effects could explain the results because each group participant viewed the selected ads in the same order, but because groups viewed the ads in a unique order, any bias in the results would likely be toward the null. Last, the ORs for the effects on ad engagement may be unstable because a disproportionately small number of participants indicated agreement to Liking or Sharing an ad.

\section{Conclusions}

Pro-drinking comments posted in response to SNS alcohol ads may significantly increase the desire to drink when combined with high user engagement values and may independently increase ad engagement. To decrease this effect, new regulations restricting the ability of SNS users to engage with SNS alcohol ads are needed. Moreover, comments may be a novel method for delivering health promotion information.

\section{Acknowledgments}

The authors acknowledge David Gregorio, who provided insight into the development and execution of this project; James Grady, who provide guidance for the statistical analysis; and Melissa Feulner, for assisting in the content analysis of the user-generated comments.

\section{References}

Alhabash, S., McAlister, A. R., Quilliam, E. T., Richards, J. I., \& Lou, C. (2015). Alcohol's getting a bit more social: When alcohol marketing messages on Facebook increase young adults' intentions to imbibe. Mass Communication \& Society, 18, 350-375. doi:10.1080/15205436.2014. 945651

Babor, T. F., \& Robaina, K. (2016). The Alcohol Use Disorders Identification Test (AUDIT): A review of graded severity algorithms and national adaptations. International Journal of Alcohol and Drug Research, 5, 17-24. doi:10.7895/ijadr.v5i2.222

Beukeboom, C. J., Kerkhof, P., \& de Vries, M. (2015). Does a virtual like cause actual liking? How following a brand's Facebook updates enhances brand evaluations and purchase intention. Journal of Interactive Marketing, 32, 26-36. doi:10.1016/j.intmar.2015.09.003

Bradburn, N., Sudman, S., \& Wansink, B. (2004). Asking questions about attitudes and behavioral intentions. In Asking questions: The definitive guide to questionnaire design - for market research, political polls, and social and health questionnaires, revised edition (pp. 117-150). San Francisco, CA: John Wiley \& Sons.

Centers for Disease Control and Prevention. (2016). Fact sheets - alcohol use and your health. Retrieved from https:/www.cdc.gov/alcohol/factsheets/alcohol-use.htm

Choi, J., \& Scott, J. (2013). Electronic word of mouth and knowledge sharing on social network sites: A social capital perspective. Journal of Theoretical and Applied Electronic Commerce Research, 8, 11-12. doi:10.4067/S0718-18762013000100006

Chu, S. C., \& Sung, Y. (2015). Using a consumer socialization framework to understand electronic word-of-mouth (eWOM) group membership among brand followers on Twitter. Electronic Commerce Research and Applications, 14, 251-260. doi:10.1016/j.elerap.2015.04.002 
Collins, S. E. (2016). Associations between socioeconomic factors and alcohol outcomes. Alcohol Research: Current Reviews, 38, 83-94.

Collins, R. L., Martino, S. C., Kovalchik, S. A., Becker, K. M., Shadel, W. G., \& D'Amico, E. J. (2016). Alcohol advertising exposure among middle school-age youth: An assessment across all media and venues. Journal of Studies on Alcohol and Drugs, 77, 384-392. doi:10.15288/ jsad.2016.77.384

Cooney, N. L., Litt, M. D., Morse, P. A., Bauer, L. O., \& Gaupp, L. (1997). Alcohol cue reactivity, negative-mood reactivity, and relapse in treated alcoholic men. Journal of Abnormal Psychology, 106, 243-250. doi:10.1037/0021-843X.106.2.243

de Vries, L., Gensler, S., \& Leeflang, P. S. H. (2012). Popularity of brand posts on brand fan pages: An investigation of the effects of social media marketing. Journal of Interactive Marketing, 26, 83-91. doi:10.1016/j. intmar.2012.01.003

France, K. E., Donovan, R. J., Bower, C., Elliott, E. J., Payne, J. M., D'Antoine, H., \& Bartu, A. E. (2014). Messages that increase women's intentions to abstain from alcohol during pregnancy: Results from quantitative testing of advertising concepts. BMC Public Health, 14(1), 30. doi:10.1186/1471-2458-14-30

Gordon, S. M., Sterling, R., Siatkowski, C., Raively, K., Weinstein, S., \& Hill, P. C. (2006). Inpatient desire to drink as a predictor of relapse to alcohol use following treatment. American Journal on Addictions, 15, 242-245. doi:10.1080/10550490600626556

Groeger, L., \& Buttle, F. (2014). Word-of-mouth marketing. European Journal of Marketing, 48, 1186-1208. doi:10.1108/EJM-02-2012-0086

Haigh, M. M., \& Wigley, S. (2015). Examining the impact of negative, user-generated content on stakeholders. Corporate Communications, 20, 63-75. doi:10.1108/CCIJ-02-2013-0010

Hoffman, E. W., Pinkleton, B. E., Weintraub Austin, E., \& ReyesVelázquez, W. (2014). Exploring college students' use of general and alcohol-related social media and their associations with alcoholrelated behaviors. Journal of American College Health, 62, 328-335. doi:10.1080/07448481. 2014.902837

Huang, J. H., Hsiao, T. T., \& Chen, Y. F. (2012, September). The effects of electronic word of mouth on product judgment and choice: The moderating role of the sense of virtual community. Journal of Applied Social Psychology, 42, 2326-2347. doi:10.1111/j.1559-1816.2012.00943.x

International Center for Alcohol Policies. (2011). Guiding principles: Self-regulation of marketing communications for beverage alcohol. Retrieved from http://www.iard.org/wp-content/uploads/2016/01/ Guiding-Principles.pdf

International Center for Alcohol Policies. (2014). Digital guiding principles: Self-regulation of marketing communications for beverage alcohol. Retrieved from http://www.k-message.com/wp-content/uploads/2014/10/ Digital-Guiding-Principles-DGPs.pdf

Jackson, K. M., Janssen, T., \& Gabrielli, J. (2018). Media/marketing influences on adolescent and young adult substance abuse. Current Addiction Reports, 5, 146-157. doi:10.1007/s40429-018-0199-6

Jernigan, D. H., \& Rushman, A. E. (2014). Measuring youth exposure to alcohol marketing on social networking sites: Challenges and prospects. Journal of Public Health Policy, 35, 91-104. doi:10.1057/jphp.2013.45

Jernigan, D., Noel, J., Landon, J., Thornton, N., \& Lobstein, T. (2017). Alcohol marketing and youth alcohol consumption: A systematic review of longitudinal studies published since 2008. Addiction, 112, Supplement 1, 7-20. doi:10.1111/add.13591

Karlamangla, A., Zhou, K., Reuben, D., Greendale, G., \& Moore, A. (2006). Longitudinal trajectories of heavy drinking in adults in the United States of America. Addiction, 101, 91-99. doi:10.1111/j. 1360-0443.2005.01299.x

Kim, E. M., \& Sun, Y. H. (2006). The effect of replies in Internet news on the audience. Korean Journal of Journalism \& Communication Studies, $50,33-64$.
Kim, E., Sung, Y., \& Kang, H. (2014). Brand followers' retweeting behavior on Twitter: How brand relationships influence brand electronic wordof-mouth. Computers in Human Behavior, 37, 18-25. doi:10.1016/j. chb.2014.04.020

Kim, J., \& Gupta, P. (2012). Emotional expressions in online user reviews: How they influence consumers' product evaluations. Journal of Business Research, 65, 985-992. doi:10.1016/j.jbusres.2011.04.013

Koroleva, K., Krasnova, H., Stimac, V., \& Kunze, D. (2011). I like it because I('M) like you-Measuring user attitudes towards information on Facebook. International Conference on Information Systems 2011, 2, 1223-1241.

Kumar, S. (2016, May 31). Cheers: 3 ways alcohol brands can join the party on Pinterest. Retrieved from https://business.pinterest.com/en/ blog/cheers-3-ways-alcohol-brands-can-join-the-party-on-pinterest

Laranjo, L., Arguel, A., Neves, A. L., Gallagher, A. M., Kaplan, R., Mortimer, N., . . L Lau, A. Y. S. (2015). The influence of social networking sites on health behavior change: A systematic review and meta-analysis. Journal of the American Medical Informatics Association, 22, 243-256. doi:10.1136/amiajnl-2014-002841

Lee, C. H., \& Cranage, D. A. (2014). Toward understanding consumer processing of negative online word-of-mouth communication. Journal of Hospitality \& Tourism Research, 38, 330-360. doi:10.1177/1096348012451455

Lee, J., \& Hong, I. B. (2016). Predicting positive user responses to social media advertising: The roles of emotional appeal, informativeness, and creativity. International Journal of Information Management, 36, 360-373. doi:10.1016/j.ijinfomgt.2016.01.001

Lim, W. M. (2015). The influence of internet advertising and electronic word of mouth on consumer perceptions and intention: Some evidence from online group buying. Journal of Computer Information Systems, 55, 81-89. doi:10.1080/08874417.2015.11645790

Lin, E. Y., Caswell, S., You, R. Q., \& Huckle, T. (2012). Engagement with alcohol marketing and early brand allegiance in relation to early years of drinking. Addiction Research and Theory, 20, 329-338. doi:10.3109 /16066359.2011.632699

Litt, M. D., Cooney, N. L., \& Morse, P. (2000). Reactivity to alcohol-related stimuli in the laboratory and in the field: Predictors of craving in treated alcoholics. Addiction, 95, 889-900. doi:10.1046/j.1360-0443.2000.9568896.x

Lobstein, T., Landon, J., Thornton, N., \& Jernigan, D. (2017). The commercial use of digital media to market alcohol products: A narrative review. Addiction, 112, Supplement 1, 21-27. doi:10.1111/add.13493

Meuter, M. L., McCabe, D. B., \& Curran, J. M. (2013). Electronic word-ofmouth versus interpersonal word-of-mouth: Are all forms of word-ofmouth equally influential? Services Marketing Quarterly, 34, 240-256. doi:10.1080/15332969.2013.798201

Molander, R. C., Yonker, J. A., \& Krahn, D. D. (2010). Age-related changes in drinking patterns from mid- to older age: Results from the Wisconsin longitudinal study. Alcoholism: Clinical and Experimental Research, 34, 1182-1192. doi:10.1111/j.1530-0277.2010.01195.x

Moore, A. A., Gould, R., Reuben, D. B., Greendale, G. A., Carter, M. K., Zhou, K., \& Karlamangla, A. (2005). Longitudinal patterns and predictors of alcohol consumption in the United States. American Journal of Public Health, 95, 458-464. doi:10.2105/AJPH.2003.019471

Morris, J. D., Choi, Y., \& Ju, I. (2016). Are social marketing and advertising communications (SMACS) meaningful? A survey of Facebook user emotional responses, source credibility, personal relevance, and perceived intrusiveness. Journal of Current Issues and Research in Advertising, 37, 165-182. doi:10.1080/10641734.2016.1171182

Myrick, H., Anton, R. F., Li, X., Henderson, S., Drobes, D., Voronin, K., \& George, M. S. (2004). Differential brain activity in alcoholics and social drinkers to alcohol cues: Relationship to craving. Neuropsychopharmacology, 29, 393-402. doi:10.1038/sj.npp.1300295 
Nhean, S., Nyborn, J., Hinchey, D., Valerio, H., Kinzel, K., Siegel, M., \& Jernigan, D. H. (2014). The frequency of company-sponsored alcohol brand-related sites on Facebook ${ }^{\mathrm{TM}}$-2012. Substance Use \& Misuse, 49, 779-782. doi:10.3109/10826084.2014.880177

Noel, J. K., \& Babor, T. F. (2017). Predicting regulatory compliance in beer advertising on Facebook. Alcohol and Alcoholism, 52, 730-736. doi:10.1093/alcalc/agx059

Noel, J. K., Babor, T. F., \& Grady, J. J. (2018a). Advertising content, platform characteristics and the appeal of beer advertising on a social networking site. Alcohol and Alcoholism, 53, 619-625. doi:10.1093/ alcalc/agy020

Noel, J. K., Xuan, Z., \& Babor, T. F. (2018b). Perceptions of alcohol advertising among high risk drinkers. Substance Use \& Misuse, 53, 1403-1410. doi:10.1080/10826084.2017.1409765

Norman, P. (2011). The theory of planned behavior and binge drinking among undergraduate students: Assessing the impact of habit strength. Addictive Behaviors, 36, 502-507. doi:10.1016/j.addbeh.2011.01.025

Paek, H. J., Hove, T., \& Jeon, J. (2013). Social media for message testing: A multilevel approach to linking favorable viewer responses with message, producer, and viewer influence on YouTube. Health Communication, 28, 226-236. doi:10.1080/10410236.2012.672912

Phua, J., \& Ahn, S. J. (2016). Explicating the 'like' on Facebook brand pages: The effect of intensity of Facebook use, number of overall 'likes,' and number of friends' 'likes' on consumers' brand outcomes. Journal of Marketing Communications, 22, 544-559. doi:10.1080/13527266.2014. 941000

Podnar, K., \& Javernik, P. (2012). The effect of word of mouth on consumers' attitudes toward products and their purchase probability. Journal of Promotion Management, 18, 145-168. doi:10.1080/10496491.201 2.668426

Proctor, D. C., Babor, T. F., \& Xuan, Z. (2005). Effects of cautionary messages and vulnerability factors on viewers' perceptions of alcohol advertisements. Journal of Studies on Alcohol, 66, 648-657. doi:10.15288/ jsa.2005.66.648

Rauniar, R., Rawski, G., Yang, J., \& Johnson, B. (2014). Technology acceptance model (TAM) and social media usage: An empirical study on Facebook. Journal of Enterprise Information Management, 27, 6-30. doi:10.1108/JEIM-04-2012-0011

Reichheld, F. F. (2003). The one number you need to grow. Harvard Business Review, 81, 46-54, 124. Retrieved from https://hbr.org/2003/12/ the-one-number-you-need-to-grow
Sandes, F. S., \& Urdan, A. T. (2013). Electronic word-of-mouth impacts on consumer behavior: Exploratory and experimental studies. Journal of International Consumer Marketing, 25, 181-197. doi:10.1080/08961530. 2013.780850

Saunders, J. B., Aasland, O. G., Babor, T. F., De La Fuente, J. R., \& Grant, M. (1993). Development of the alcohol use disorders identification test (AUDIT): WHO collaborative project on early detection of persons with harmful alcohol consumption-II. Addiction, 88, 791-804. doi:10.1111/j.1360-0443.1993.tb02093.x

Schulze, D., \& Jones, B. T. (2000). Desire for alcohol and outcome expectancies as measures of alcohol cue-reactivity in social drinkers. Addiction, 95, 1015-1020. doi:10.1046/j.1360-0443.2000.95710154.x

Scott, S., Muirhead, C., Shucksmith, J., Tyrrell, R., \& Kaner, E. (2017). Does industry-driven alcohol marketing influence adolescent drinking behaviour? A systematic review. Alcohol and Alcoholism, 52, 84-94. doi:10.1093/alcalc/agw085

See-To, E. W. K., \& Ho, K. K. W. (2014). Value co-creation and purchase intention in social network sites: The role of electronic Word-of-Mouth and trust - A theoretical analysis. Computers in Human Behavior, 31, 182-189. doi:10.1016/j.chb.2013.10.013

Sohn, D. (2009). Disentangling the effects of social network density on electronic word-of-mouth (eWOM) intention. Journal of Computer-Mediated Communication, 14, 352-367. doi:10.1111/j. 1083-6101.2009.01444.x

Tapert, S. F., Cheung, E. H., Brown, G. G., Frank, L. R., Paulus, M. P., Schweinsburg, A. D., . . Brown, S. A. (2003). Neural response to alcohol stimuli in adolescents with alcohol use disorder. Archives of General Psychiatry, 60, 727-735. doi:10.1001/archpsyc.60.7.727

Toldos-Romero, M. P., \& Orozco-Gómez, M. M. (2015). Brand personality and purchase intention. European Business Review, 27, 462-476. doi:10.1108/EBR-03-2013-0046

Winpenny, E. M., Marteau, T. M., \& Nolte, E. (2014). Exposure of children and adolescents to alcohol marketing on social media websites. Alcohol and Alcoholism, 49, 154-159. doi:10.1093/alcalc/agt174

Wu, P. F. (2013). In search of negativity bias: An empirical study of perceived helpfulness of online reviews. Psychology and Marketing, 30, 971-984. doi:10.1002/mar.20660

YLE. (2014, February 27). Government imposes further restrictions on alcohol advertising. Uutiset. Retrieved from https://yle.fi/uutiset/osasto/ news/government_imposes_further_restrictions_on_alcohol_advertising/7112320 